EPiC Series in Engineering
Volume 3, 2018, Pages 2144-2154
HIC 2018. 13th International
Conference on Hydroinformatics

\title{
Towards a web decision system support for planning micro- watershed using pressure-state-response and logic fuzzy with study case in Colombia
}

\author{
Viviana Vargas-Franco ${ }^{1}$, Inés Restrepo-Tarquino ${ }^{2}$ \\ ${ }^{1}$ National University of Colombia, Carrera 32 No. 12-00, Palmira, 76001, Colombia \\ ${ }^{2}$ University of Valle, Calle 13 \# 100-00, Cali, 76001, Colombia
}

Corresponding author: vvaargasf@unal.edu.co

\begin{abstract}
This paper presents a conceptual web decision support systems (DSS) for assessment of a tropical Andean micro-watershed. A combination of pressure-state-response (PSR) indicators and logic fuzzy were used. Three indices were defined: climate change (ICC), quality water (IQW) and soil degradation (ISD). Each index is a combination of qualitative and quantitative indicators. Fuzzy functions were defined to generate operability in each index. Trapezoidal, triangular and singleton functions were defined. The inputs are the indicators value in each zones of the watershed: high zone, medium zone and low zone. Outputs of WebDSS are the value of each index. The Web DSS was applied in an Andean watershed named "El Chocho", in Colombia. The results indicate the high degradation level in the watershed, evidenced by the indices values. This study indicates the possibility of building and applying a DSS to support management decision process in Andean microwatersheds.
\end{abstract}

Keywords: Logic fuzzy, micro-watershed in Colombia, Pressure-State-Response (PER) framework, Web Decision System Support (DSS)

\section{Introduction}

Tropical watershed faces many problems that hamper its sustainability, such as land degradation, water pollution, water scarcity and several socio-economic pressures [1]. Watersheds and rivers are vital ecological features for the provision of hydrological services for the health, welfare and prosperity of human communities. Nevertheless, anthropogenic activities coupled with climate change and climate variability are blamed for degrading watersheds and rivers and decreasing their 
capacity to irrigate [2]. The Andean region holds $9.5 \%$ of the world's fresh water reserves and plays the pivotal role of providing water for most South American watersheds. However, unsustainable practices such as overgrazing in the water recharging zones, deforestation, mining, deficiencies in practices agriculture, changes on the use land and climate changes, directly impact their surrounding environment and water resource. Watershed management planning is a complex task involving a variety factors and stakeholders. This paper presents conceptual and operative web decision support systems (DSS) for assessment of an integrated tropical Andean watershed. A combination of pressure-state-response (PSR) indicators and logic fuzzy were used. An application was development in in an Andean watershed named "El Chocho", in Colombia.

\section{Materials and methods}

A conceptual and operative web Decision Support System was built through definition of three main index: climate change (ICC), quality water (IQW) and soil degradation (ISD). Each index is a combination of Pressure-State-Response indicators and fuzzy logic function. The PSR model is based on the concept of causality: human activities exert pressures on the environment $(\mathrm{P})$ and change its quality and quantity of natural resources (S). Society responds to these changes through environmental, general economic and sectorial responses (R). The theory of fuzzy logic provides a mathematical strength to capture the uncertainties associated with human cognitive processes, such as thinking and reasoning. Fuzzy logic has been proposed as a systematic tool for assessment of sustainability [3]. The PSR model was originally developed by the Organization for Economic Co-operation and Development [4] and provides a mechanism to monitor and evaluated the status of the environmental [5]. The indicators were defined by both literature review and conceptual relation between variables.

\subsection{Pressure-State-Response (PSR) model}

The PSR model aims to develop indicators of sustainable development, organized in three categories: pressure $(\mathrm{P})$, state $(\mathrm{S})$ and response $(\mathrm{R})$. The PSR framework is based on a concept of causality, covers causes and effects influencing a measurable state and seems highly capable of showing information to end users in a causal way by differentiating between causes, effects and human responses to control the extent of anthropogenic impacts on nature [6]. Indicators of Pressure (P) perceived causes of adverse environmental effects [7], answer the questions: why is it happening? and what social, political, economic, market and other forces are involved? and these observations show: the range of stresses or pressures from human activities that result in environmental change. These describe pressures on the environment originating from human activities, changing quality and quantity of natural 
resources. Indicators of State (S) answer the question: what is happening to the state of the environment of natural resources? and these observations show: changes or trends in the physical or biological state of the natural world. These are designed to describe the status quo of the environment and the quality and quantity of resources and their changes over time. Indicators of Response (R) answer the question; what are we doing about the state and pressure, or what can be done about it? and these observations show: actions adopted in response to environmental problems and concerns. These responses will themselves become pressure and state. These show to which degree society is responding to environmental changes and concerns. This could be the number and kind of measures taken, the efforts of implementing or the effectiveness of those measures and responses may range from public to private sector activities. Society responds to through environmental, general economic and sectorial policies and through changes in awareness and behaviour, with adaptive, preventive, and mitigated actions [8].

\subsection{Logic fuzzy model}

For each indicator PRS was defined one fuzzy logic function, the values were selected through literature review. The fuzzy logic was introduced by L. A. Zadeh in 1965. Fuzzy logic provides an inference morphology that enables approximate human reasoning capabilities to be applied to knowledge-based systems. The theory of fuzzy logic provides a mathematical strength to capture the uncertainties associated with human cognitive processes, such as thinking and reasoning. Fuzzy logic has been proposed as a systematic tool for assessment of sustainability. Fuzzy logic can represent uncertain data, emulating skilled humans, and handling vague situation where traditional mathematics is ineffective and is a scientific tool that permits modelling a system without detailed mathematical descriptions using qualitative as well as quantitative data [9]. The fuzzy logic is based on IF condition THEN conclusion type rules. These rules are involving vague linguistic expressions modelled by fuzzy sets. Considering the general set of rules of the following example, as being the core of a fuzzy decision system, IF (condition11) AND/OR (condition21) ... (conditionn1) THEN conclusion1; IF (condition12) AND/OR (condition22) ... (conditionm2) THEN conclusion 2; ....; IF (condition1p) AND/OR (condition2p) ... (conditionlp) THEN conclusionp, where each of the conditions involves a considered input of the system. The standard operators which are satisfying the standard requirements for fuzzy conjunction, disjunction and negation are the triangular norm (t-norm), triangular conorm ( $\mathrm{t}$-conorm) and negation. General issues to be taken into consideration before designing a system based on fuzzy logic are: i) an expert is always needed in the design phase; ii) using fewer rules it is easier to understand the system behaviour; iii) it is not necessary to implement all the possible rules; iv) the system may be tuned by modifying the membership functions. There is a commonly used in the fuzzy logic approach to measure the performance 
with the pair of numbers $(\mathrm{xc}, \mathrm{yc})$ as coordinates of the centre of mass (the so called "centroid method").

\subsection{Study area}

The micro-watershed el Chocho is located on the eastern side of the western branch $\left(3.30^{\circ} \mathrm{N}, 76.34^{\circ} \mathrm{W}\right)$ in the Department of Valle del Cauca, in Colombia. The Chocho has $10 \mathrm{~km}$ long and $20 \mathrm{~km}^{2}$, catchment is home about 15.000 people in a rural area that is however strongly influenced by the proximity of the city [6]. The elevation ranges from 950 to $2.000 \mathrm{~m}$ above sea level. It is situated in a humid tropical zone with 2,495 mm.yr-1 of its annual mean precipitation over the last 20 years; meanwhile, the annual mean temperature over the last 10 years was $23.10^{\circ} \mathrm{C}$. This micro-watershed has suffered a huge environmental damage, because of the change in the use of the land, the increase of the population, the discharge of untreated domestic wastewater, the poor management of the solid wastes, and the discharge of the acid coal water. See Figure 1.
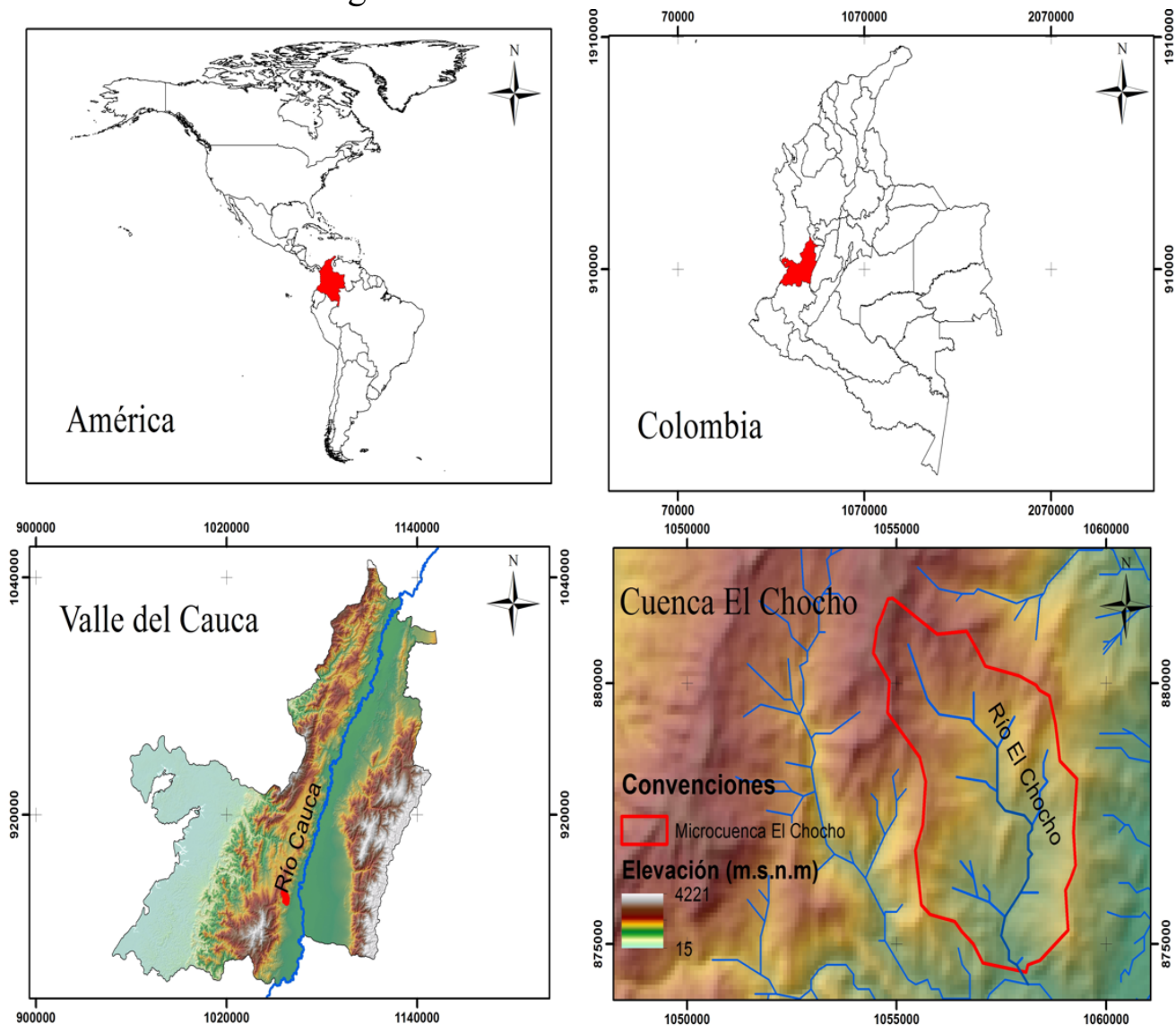

Figure.1. Localization of Chocho micro-watershed in Colombia. 
Towards a Web Decision System Support for Planning ... V. Vargas-Franco and I. Restrepo-Tarquino

\section{Results}

\subsection{Conceptual DSS model}

A DSS was construed through combination of PSR model and fuzzy logic. The conceptual structure is shown in Figure 2. The inputs are the indicators PSR values in each zone in a watershed. The inputs of each indicator are provided by the user through knowledge, information or data. By using fuzzy logic functions and IFTHEN rules, these inputs are combined to build a composites index as output.

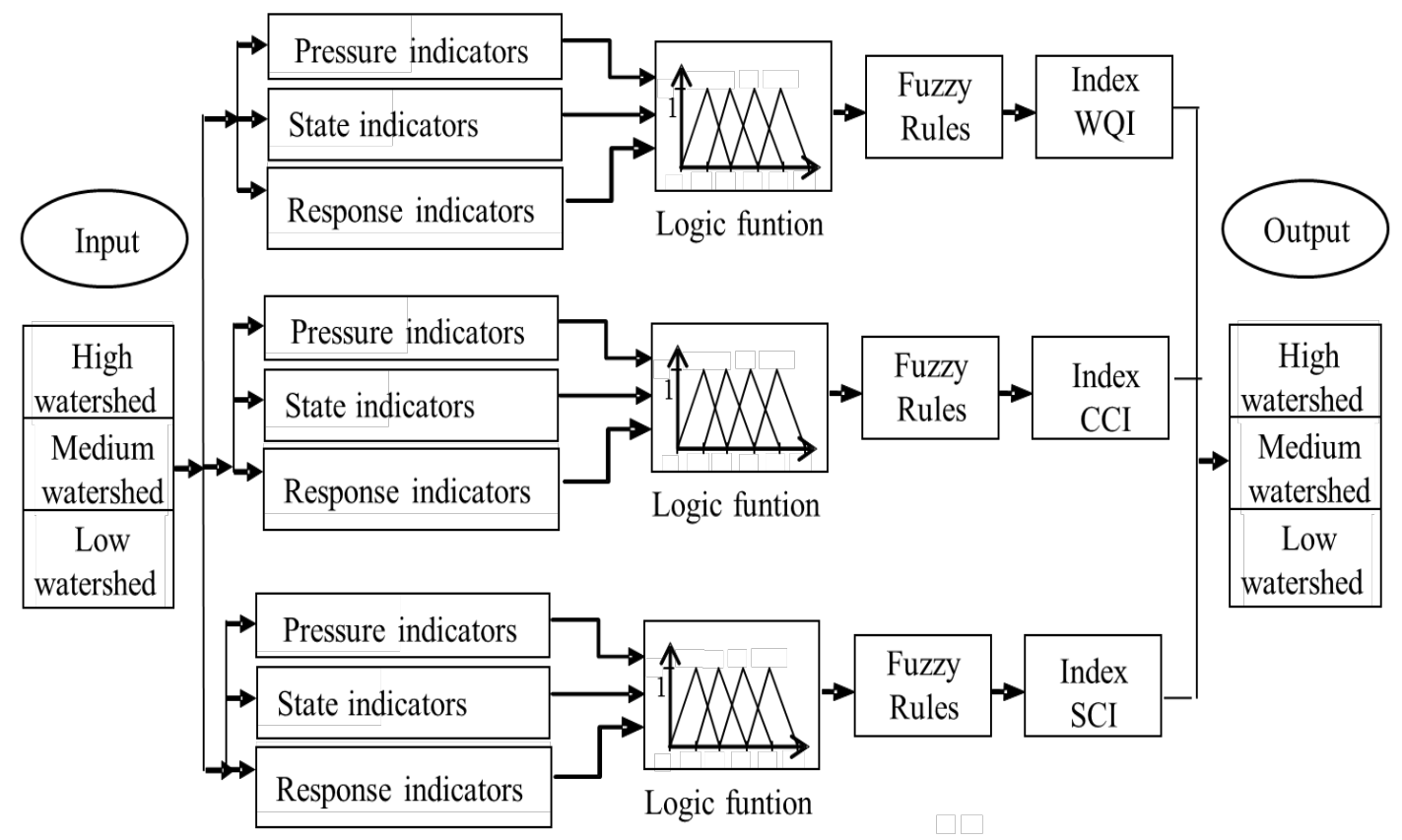

Figure. 2. Conceptual flowchart of the model DSS used to planning management watershed.

\subsection{Pressure-State-Response (PSR) indicators}

PRS indicators were defined as quantitative and qualitative components. In table 1 is presented the set indicators proposal. To evaluate these indicators can be used a combination of field data, models and expert knowledge. 
Towards a Web Decision System Support for Planning ... V. Vargas-Franco and I. Restrepo-Tarquino

Table 1. Pressure-State-Response indicators for three index to planning management watershed

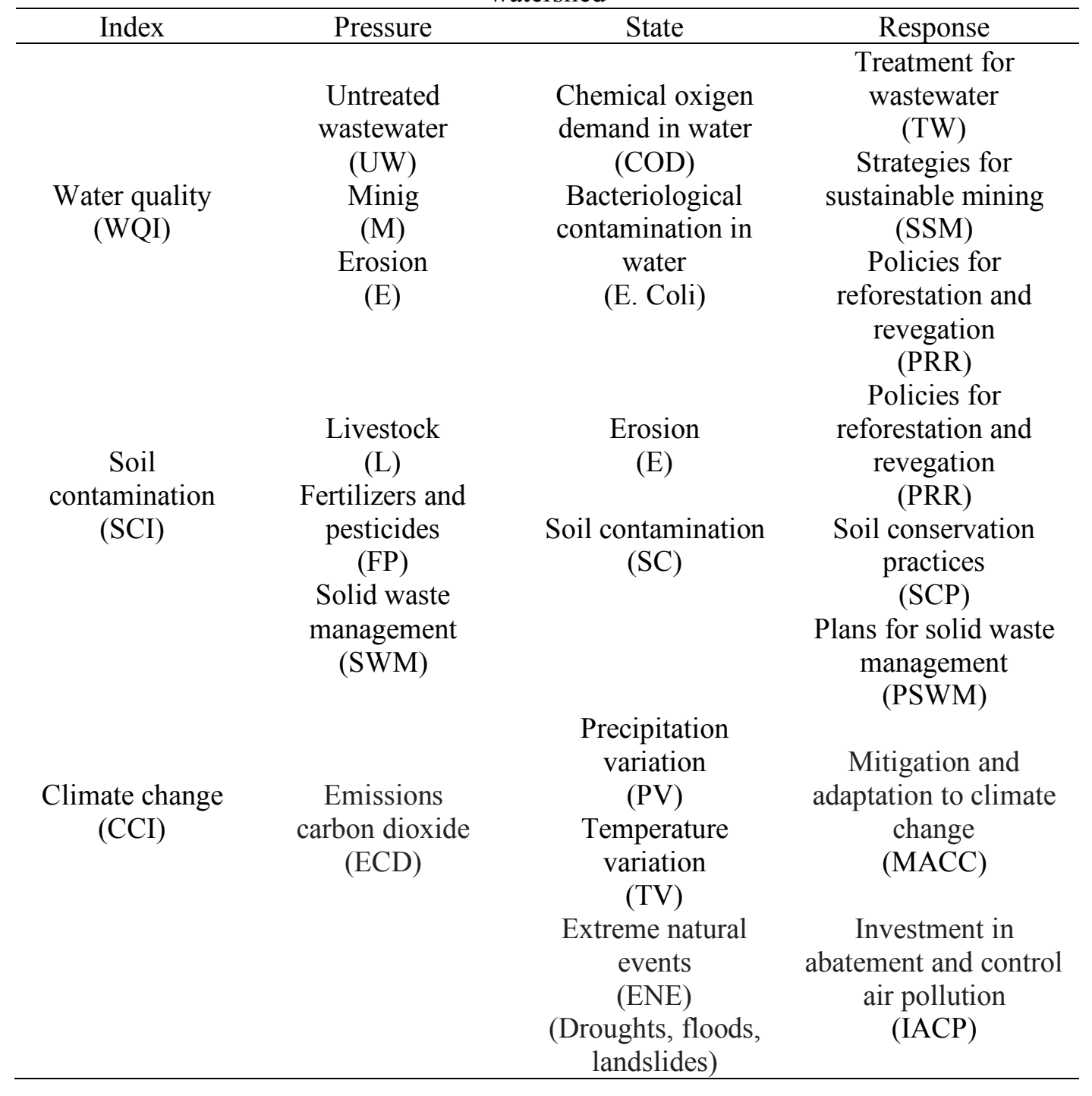

\subsection{Logic funtions}

Triangular, singleton, trapezoidal funtions were assigned to each PSR indicator. These funtions were defined through of both literature review and expert judgement. An example of logic funtions is shown in the figure 3 and the figure 4 presents the pressure-state-response fuzzy logic on value of water quality index (WQI). The main advantage of Fuzzy analysis is the ability to deal with imprecise, unciertain, or ambiguos data or relationship, with clearly fits the study of ecologial and enviroment issues [11]. 
Towards a Web Decision System Support for Planning ... V. Vargas-Franco and I. Restrepo-Tarquino
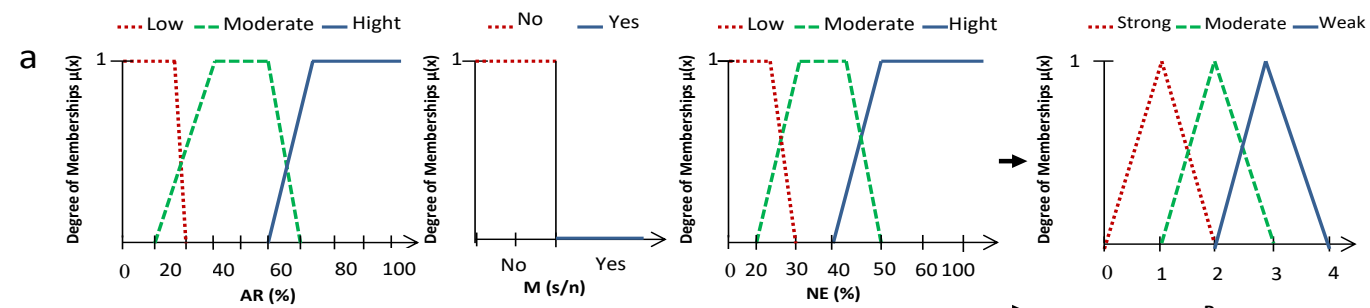

b
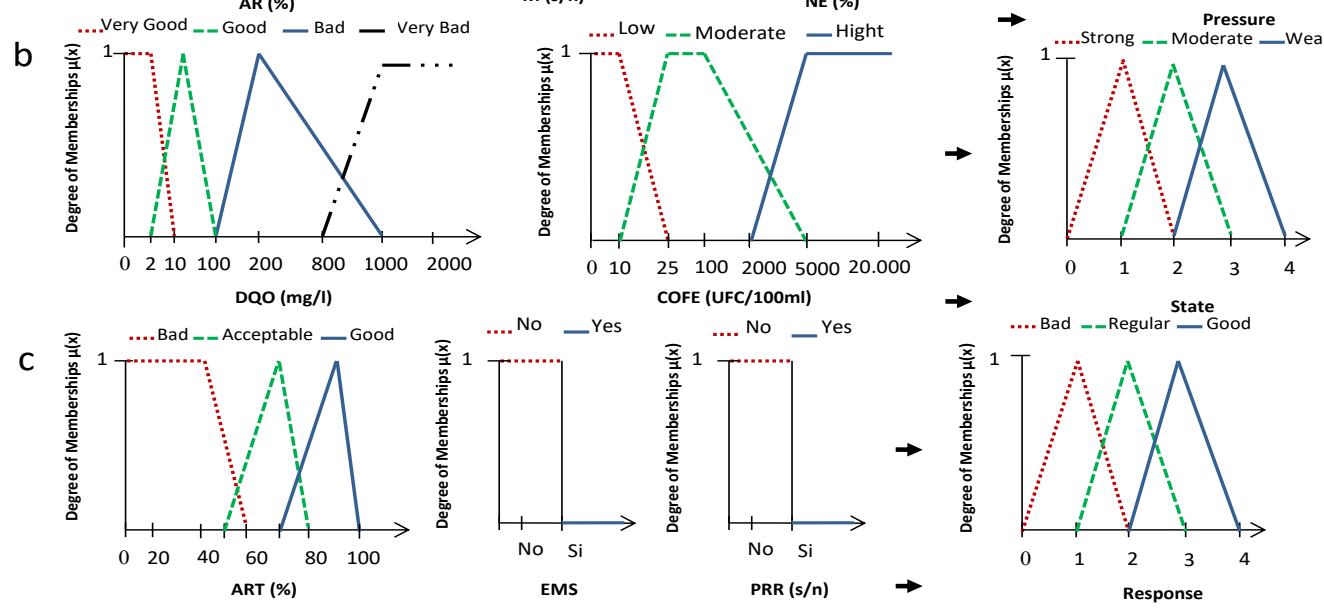

Figure 3. Membership funtions of fuzzy values for linguistic variables (a) "state", (b) "pressure", (c) "response"
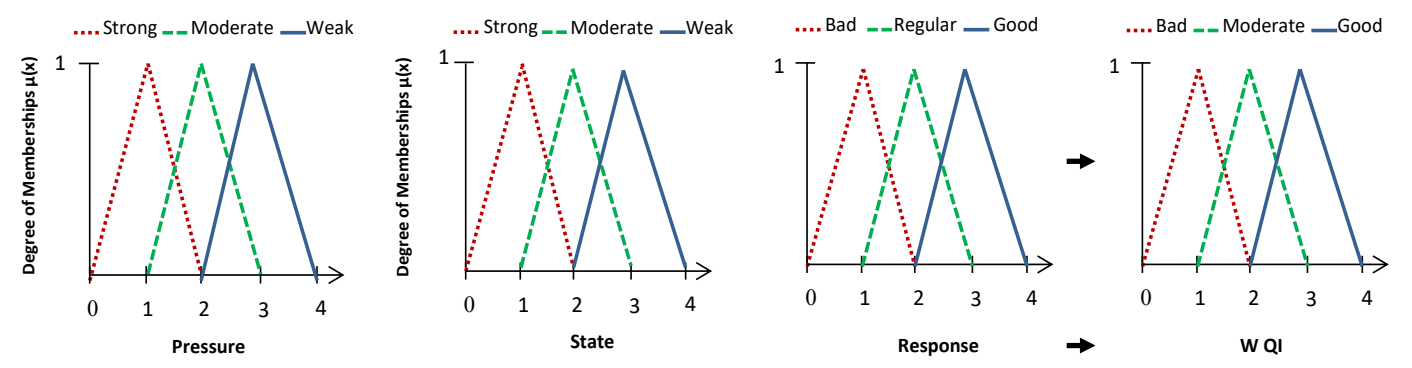

Figure 4. Membership funtions of fuzzy values of Water Quality Index (WQI)

\subsection{Example of rules}

PSR indicators were assessed by means of fuzzy inference systems through decision rules. In table 2 is presented an example of some rules in the decision support system (DSS) for planning management in watershed. The rules were defined through literature review and knowledge management. 
Towards a Web Decision System Support for Planning ... V. Vargas-Franco and I. Restrepo-Tarquino

Table 2. Example of decision rules for State value in the index WQI.

\begin{tabular}{|c|c|c|c|c|}
\hline $\begin{array}{l}\text { Rule } \\
\text { No. }\end{array}$ & COD & E. Coli & State & RULE \\
\hline 19 & $\begin{array}{l}\text { Very Good } \\
\text { (VG) }\end{array}$ & Low (L) & Weak (W) & $\begin{array}{l}\text { IF (COD IS VG) AND (E. Coli IS L) } \\
\text { THEN State IS Weak }\end{array}$ \\
\hline 20 & $\begin{array}{l}\text { Very Good } \\
\text { (VG) }\end{array}$ & $\begin{array}{l}\text { Moderate } \\
(\mathrm{M})\end{array}$ & $\begin{array}{l}\text { Moderate } \\
\text { (M) }\end{array}$ & $\begin{array}{l}\text { IF (CDO IS VG) AND (E. Coli IS } \\
\text { M) THEN State IS Moderate }\end{array}$ \\
\hline 21 & $\begin{array}{l}\text { Very } \\
\text { Good(VG) }\end{array}$ & $\operatorname{Hight}(\mathrm{H})$ & Strong (S) & $\begin{array}{l}\text { IF (COD IS VG) AND (E. Coli IS H) } \\
\text { THEN State IS Strong }\end{array}$ \\
\hline 22 & Good (G) & Low (L) & Weak (W) & $\begin{array}{l}\text { IF (COD IS G) AND (E. Coli IS L) } \\
\text { THEN State IS Weak }\end{array}$ \\
\hline 23 & Good $(\mathrm{G})$ & $\begin{array}{l}\text { Moderate } \\
(\mathrm{M})\end{array}$ & $\begin{array}{l}\text { Moderate } \\
\text { (M) }\end{array}$ & $\begin{array}{l}\text { IF (COD IS G) AND (E. Coli IS M) } \\
\text { THEN State IS Moderate }\end{array}$ \\
\hline 24 & Good (G) & $\operatorname{Hight}(\mathrm{H})$ & Strong (S) & $\begin{array}{l}\text { IF (COD IS G) AND (E. Coli IS H) } \\
\text { THEN State IS Strong }\end{array}$ \\
\hline 25 & $\operatorname{Bad}(\mathrm{B})$ & Low (L) & $\begin{array}{l}\text { Moderate } \\
\text { (M) }\end{array}$ & $\begin{array}{l}\text { IF (COD IS B) AND (E. Coli IS L) } \\
\text { THEN State IS Moderate }\end{array}$ \\
\hline 26 & $\operatorname{Bad}(\mathrm{B})$ & $\begin{array}{l}\text { Moderate } \\
(\mathrm{M})\end{array}$ & Strong (S) & $\begin{array}{l}\text { IF (COD IS B) AND (E. Coli IS M) } \\
\text { THEN State IS Strong }\end{array}$ \\
\hline 27 & $\operatorname{Bad}(\mathrm{B})$ & $\operatorname{Hight}(\mathrm{H})$ & Strong (S) & $\begin{array}{l}\text { IF (COD IS B) AND (E. Coli IS H) } \\
\text { THEN State IS Strong }\end{array}$ \\
\hline 28 & $\begin{array}{l}\text { Very Bad } \\
\text { (VB) }\end{array}$ & Low (L) & Strong (S) & $\begin{array}{l}\text { IF (COD IS VB) AND (E. Coli IS L) } \\
\text { THEN State IS Strong }\end{array}$ \\
\hline 29 & $\begin{array}{l}\text { Very Bad } \\
\text { (VB) }\end{array}$ & $\begin{array}{l}\text { Moderate } \\
(\mathrm{M})\end{array}$ & Strong (S) & $\begin{array}{l}\text { IF (COD IS VB) AND (E. Coli IS } \\
\text { M) THEN State IS Strong }\end{array}$ \\
\hline 30 & $\begin{array}{l}\text { Very Bad } \\
\text { (VB) }\end{array}$ & $\operatorname{Hight}(\mathrm{H})$ & Strong (S) & $\begin{array}{l}\text { IF (COD IS VB) AND (E. Coli IS H) } \\
\text { THEN State IS Strong }\end{array}$ \\
\hline
\end{tabular}

\subsection{Interphase of Web Decision Suport System}

World Wibe Web technologies have changed the process to build a DSS in all phases: design, development, implementation, development and monitoring of decision support systems. User interface refers to the way a manager or knowledge worker can use the system to support his or her decision-making needs without having to become an expert in its technology. User interface includes bi-directional human-computer communication and its management. In figure 5 y figure 6 , is presented an interphase of the web decision support system. It was developed with deafferents computer programmes: Web Ajax, JfuzzyLogic, Java Servlets, Java and framework jQuery. 
Towards a Web Decision System Support for Planning ... V. Vargas-Franco and I. Restrepo-Tarquino

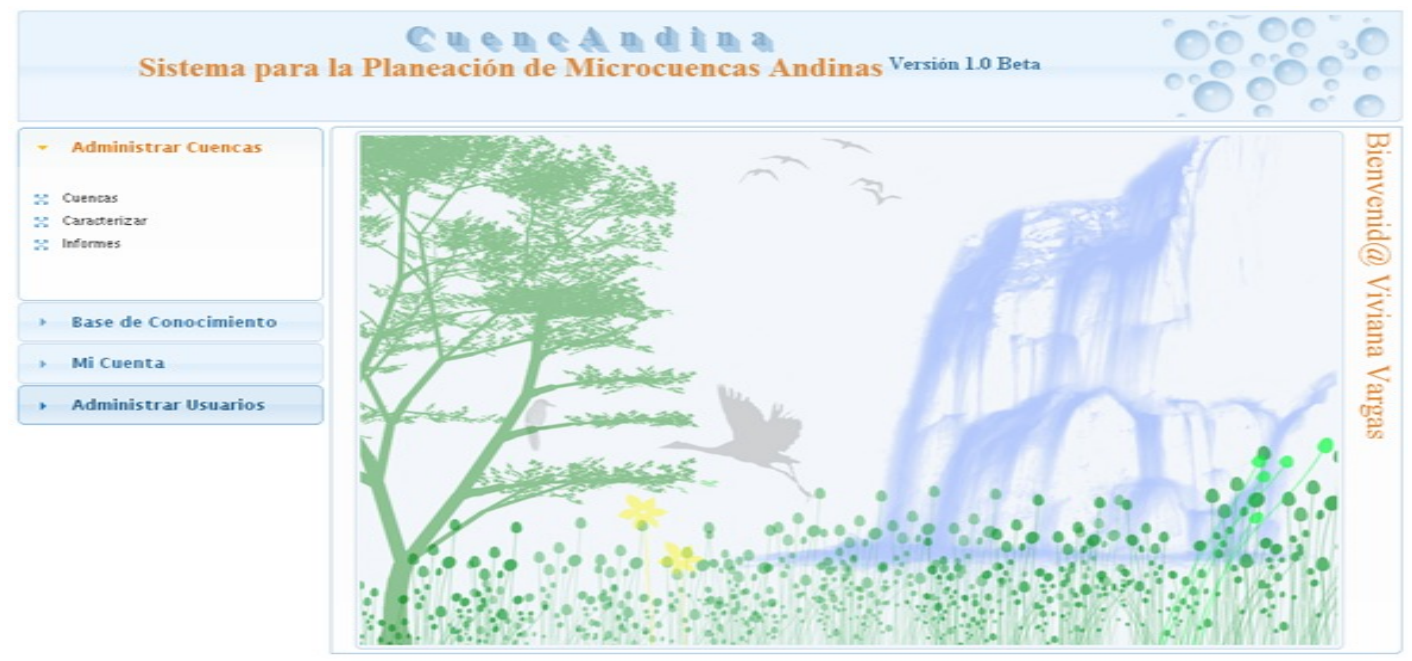

Figure. 5. Example of user interface in the Web-DSS cuencandina 1.0.

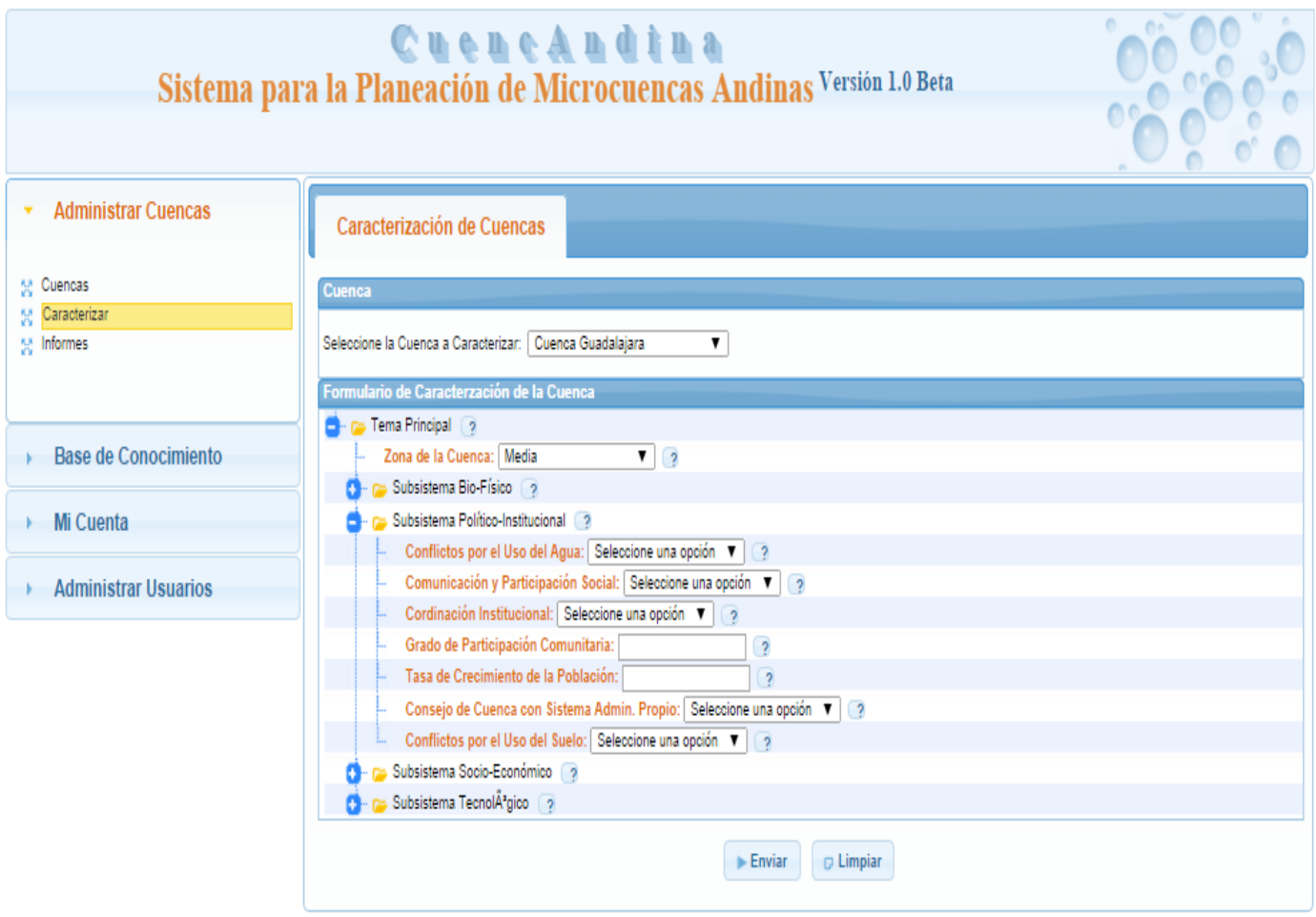

Figure. 6. Example of user interface related with indicators Pressure-State-Response in Web-DSS cuencandina 1.0. 
Towards a Web Decision System Support for Planning ... V. Vargas-Franco and I. Restrepo-Tarquino

\subsection{Evaluation in micro-watershed el Chocho in Colombia}

Indicators were applied to the micro-watershed El Chocho. These were evaluated considering both information and data secondary. Each dataset was collected from reliable local authorities. As an example, the three indices were bad in each zone of micro watershed.

\section{Conclusions}

Using artificial intelligence as linguistic variables, linguistic rules and pressure-stateresponse indicators were built an approximation of a DSS, with three indexes to an assessment of sustainable in a micro-watershed. The three indexes are: water quality index (WQI), soil contamination index (SCI) and climate change index (CCI). This DSS is a new model that combines pressure-state-response indicators with fuzzy logic for planning management in micro-watershed. One application was carried out in Valle del Cauca Colombia in the Chocho micro-watershed. This DSS showed the critical situation of this micro-watershed in aspects of water quality, soil contamination and climate change. The case study showed the utility of this tools to support decision-maker on way easy, fast and understanding. More applications are necessaries and others complementary indices too. This DSS can be applied to similar Andean watershed.

\section{References}

[1] R. Firdaus, N. Nakagoshi, A. Idris, Sustainability Assessment of Humid Tropical Watershed: A Case of Batang Merao Watershed, Indonesia, Procedia Environmental Sciences 20 (2014) 722-731.

[2] M.C.S. Lalika, P. Meire, Y.M. Ngaga, L. Chang'a, Understanding watershed dynamics and impacts of climate change and variability in the Pangani River Basin, Tanzania, Ecohydrology \& Hydrobiology 15 (2015) 26-38.

[3] L.A. Andriantiatsaholiniaina, V.S. Kouikoglou, Y.A. Phillis, Evaluating strategies for sustainable development: fuzzy logic reasoning and sensitivity analysis, Ecological Economics 48 (2004) 149- 172.

[4] OECD, Towards sustainable development. Environmental Indicators, Red de Desarrollo Sostenible - PNUD (1998).

[5] X.C. Zhanga, C. Ma, S.F. Zhan, W.P. Chen, Evaluation and simulation for ecological risk based on emergy analysis and Pressure-State-Response Model in a coastal city, China, Procedia Environmental Sciences 13 (2012) 221 - 231.

[6] I.C. Domínguez, S.M. Corrales, Caso de estudio. Microcuenca de la Quebrada el Chocho, Santiago de Cali. Valle del Cauca. Colombia, IWMI; CGIAR y CINARA 14 (2006) 675-684.

[7] Ken F.D. Hughey, Ross Cullen, Geoff N. Kerr, Andrew J. Cook, Application of the pressure-state-response framework to perceptions reporting of the state of the New Zealand environment, Journal of Environmental Management 70 (2004) 85-93. 
Towards a Web Decision System Support for Planning ... V. Vargas-Franco and I. Restrepo-Tarquino

[8] Joana H. Martins, Ana S. Camanho, Miguel B. Gaspar, A review of the application of driving forces e Pressure e State e Impact e Response framework to fisheries management, Ocean \& Coastal Management 69 (2012) 273-281.

[9] Luc A. Andriantiatsaholiniaina, Vassilis S. Kouikoglou, Yannis A. Phillis, Evaluating strategies for sustainable development: fuzzy logic reasoning and sensitivity analysis, Ecological Economics 48 (2004) 149- 172. 